\title{
First identification of a Cathaysian continental fragmanent beneath the Gagua Ridge, Philippine Sea, and its tectonic implications
}

Shengping Qian ${ }^{1 * *}$, Xiaozhi Zhang ${ }^{1}$, Jonny $\mathbf{W u}^{2}$, Serge Lallemand ${ }^{3}$, Alexander R.

L. Nichols ${ }^{4}$, Chiyue Huang ${ }^{1,5}$, Daniel P. Miggins ${ }^{6}$, Huaiyang Zhou ${ }^{\text {* }}$

${ }^{1}$ State Key Laboratory of Marine Geology, Tongji University, Shanghai 200092,

China

${ }^{2}$ Department of Earth \& Atmospheric Sciences, University of Houston, Houston, Texas 77204, USA

${ }^{3}$ Géosciences Montpellier, CNRS, Montpellier University, 34095 Montpellier cédex 5, France

${ }^{4}$ School of Earth and Environment, University of Canterbury, Christchurch 8140, New Zealand

${ }^{5}$ Department of Earth Sciences, National Cheng Kung University, 701 Tainan,

Taiwan

${ }^{6}$ College of Earth, Ocean and Atmospheric Sciences, Oregon State University, Corvallis, OR 97331, USA

\section{Contents}

\section{Analytical methods}

Whole-rock major and trace element, and Sr-Nd-Pb-Hf isotopes.

In situ U-Pb dating and Hf isotope analyses of zircon.

${ }^{40} \mathrm{Ar} /{ }^{39} \mathrm{Ar}$ Geochronology at Oregon State University

\section{Supplementary Figures}

Fig. DR1. Swath bathymetry of the sampling area.

Fig. DR2. Petrographic features of the Gagua Ridge (GR) lavas.

Fig. DR3. Concordia plots and CL images of zircons from the GR lavas. 
Fig. DR4. (A) Sr/Th vs. Th/Ce and (B) Ba/La vs. Th/Yb diagrams for the GR lavas.

\section{Supporting References}

\section{Tables (uploaded separately)}

Table DR1. Major and trace element, and Sr-Nd-Hf-Pb isotope composition of the GR lavas.

Table DR2. U-Pb dating results for zircons in the GR lavas.

Table DR3. Trace element data for zircons in the GR lavas.

Table DR4. Hf isotopic data for zircons in the GR lavas.

Table DR5. Input parameters of numerical modelling for the contribution of slabderived components to the GR lavas.

Table DR6. Trace element and isotope compositions of international standards.

Table DR7. Ages and trace element (ppm) compositions of Zircon standards.

Table DR8. Hf isotope compositions of Zircon standards.

Table DR9. Ar-Ar dating data for plagiolcase in the GR lavas.

\section{Analytical methods}

Whole-rock major and trace element, and Sr-Nd-Pb-Hf isotopes

After removal of weathered or altered surfaces, the fresh parts of samples were selected for chemical analysis. Whole-rock major element compositions were determined on fused glass discs by X-ray fluorescence (XRF) techniques in the State Key Laboratory of Marine Geology (SKLMG) at Tongji University. Trace element concentrations were measured using a inductively coupled plasma-mass spectrometry (ICP-MS) after acid digestion of samples in high-pressure Teflon bombs in the SKLMG at Tongji University. The trace element data for standards AGV-2, BHVO-2 and BCR-2 agree within about 5\% with reference values (Table DR6).

$\mathrm{Sr}-\mathrm{Nd}-\mathrm{Pb}-\mathrm{Hf}$ isotopic ratios were measured using a Neptune Plus multi-collector (MC)-ICP-MS at the Guangzhou Institute of Geochemistry, Chinese Academy of Science (GIG-CAS). The measured ${ }^{143} \mathrm{Nd} /{ }^{144} \mathrm{Nd}$ and ${ }^{87} \mathrm{Sr} /{ }^{86} \mathrm{Sr}$ ratios were normalized to ${ }^{146} \mathrm{Nd} /{ }^{144} \mathrm{Nd}=0.7219$ and ${ }^{86} \mathrm{Sr} /{ }^{88} \mathrm{Sr}=0.1194$, respectively. $\mathrm{Pb}$ isotope ratios were normalized for instrumental mass fraction relative to NBS/SRM $997{ }^{203} \mathrm{Tl} /{ }^{205} \mathrm{Tl}=$ 0.41891. The standard SRM981 was used to monitor the instrument drift during the analysis of $\mathrm{Pb}$ isotopes. Hf isotopic ratios were corrected for mass fractionation and external calibration by normalizing to ${ }^{179} \mathrm{Hf} /{ }^{177} \mathrm{Hf}=0.7325$ and ${ }^{176} \mathrm{Hf} /{ }^{177} \mathrm{Hf}=$ 0.282160 of the standard JMC475. The ${ }^{87} \mathrm{Sr} /{ }^{86} \mathrm{Sr},{ }^{143} \mathrm{Nd} /{ }^{144} \mathrm{Nd},{ }^{206} \mathrm{~Pb} /{ }^{204} \mathrm{~Pb},{ }^{207} \mathrm{~Pb} /{ }^{204} \mathrm{~Pb}$, 
${ }^{208} \mathrm{~Pb} /{ }^{204} \mathrm{~Pb}$ and ${ }^{176} \mathrm{Hf} /{ }^{177} \mathrm{Hf}$ values of standard $\mathrm{W}-2$, BHVO-2, and BCR-2 are consistent with the reported values (Table DR6).

\section{In situ $U-P b$ dating and Hf isotope analyses of zircon}

After being separated from whole rock samples following traditional methods of jaw crushing and pulverizing, zircons from four samples were separated by density separation using heavy-liquid (methylene iodide) and magnetic separation using a Frantz magnetic separator, and then purified by hand picking under a binocular microscope. Great care was taken to avoid cross-contamination when collecting zirocns for $\mathrm{U}-\mathrm{Pb}$ and $\mathrm{Hf}$ isotope analyses. A total of 193 zircon grains were picked out from all the samples. The number of zircons from the four samples (D7-1-30, D7-1$18, \mathrm{D} 7-1-24, \mathrm{D} 7-1-42)$ is 23, 37, 103 and 30, respectively. As D7-1-24 is much heavier $(\sim 6 \mathrm{~kg})$ than other samples $(\sim 2 \mathrm{~kg})$, there are more zirocns (exceeding the sum of other samples) separated from it. Zircon crystals vary in morphology and texture from euhedral to subhedral, including large ( $200 \mu \mathrm{m}$ in length) and elongated zircons (Fig. DR3). Cathodoluminescence (CL) images were taken for all zircons in the SKLMG at Tongji University. Zircon U-Pb dating and trace element analysis were carried out by LA-ICP-MS (a RESOlution M-50 laser ablation system and a Thermo Element 2 instrument) in the GIGCAS, China. The surface of each zircon crystal was cleaned with ethanol to eliminate possible contamination before analysis. The analysis spot was about $32 \mu \mathrm{m}$ in diameter, the repetition rate was $5 \mathrm{~Hz}$. Each analysis incorporated a background acquisition of $30 \mathrm{~s}$ (gas blank) followed by $50 \mathrm{~s}$ data acquisition from the sample. In order to monitor the external uncertainties of $\mathrm{U}-\mathrm{Pb}$ zircon measurements, the standard zircons Plešovice and GJ-1 were alternately analyzed as unknowns. Common $\mathrm{Pb}$ was corrected using the Excel program ComPbCorr\#_151 (Andersen, 2002). Off-line calculations of isotopic ratios were performed using software GLITTER. The trace element compositions of zircons were calibrated against standards BHVO-2, BCR-2G and BIR-1G (Zhang et al., 2019). Each analysis incorporated a background acquisition of approximately 20-30 s (gas blank) and $50 \mathrm{~s}$ data acquisition from the sample. The $\mathrm{U}-\mathrm{Pb}$ dating results and trace element analyses for zircon standard Plešovice and GJ-1 are shown in Table DR7.

Hafnium isotope compositions in zircon crystals were measured using a Neptune Plus MC-ICP-MS (Thermo Scientific) combined with a RESOlution M-50 $193 \mathrm{~nm}$ laser ablation system at the GIGCAS. The zircon grains selected for Hf isotope analysis were those for which $\mathrm{U}-\mathrm{Pb}$ had been measured. The typical laser spot size for zircon Hf analysis was $44 \mu \mathrm{m}$ in diameter, with an ablation time of $26 \mathrm{~s}$, a repetition rate of $10 \mathrm{~Hz}$, and laser beam energy density of $10 \mathrm{~J} / \mathrm{cm}^{2}$. Corrections for isobaric 
interference of ${ }^{176} \mathrm{Lu}$ and ${ }^{176} \mathrm{Yb}$ on ${ }^{176} \mathrm{Hf}$ must be made precisely. Applying an exponential law and a ${ }^{176} \mathrm{Yb} /{ }^{171} \mathrm{Yb}$ of 0.897145 (Segal et al., 2003), ${ }^{171} \mathrm{Yb}$ was measured and corrected for the isobaric interference of ${ }^{176} \mathrm{Yb}$ (Segal et al., 2003). To correct for the isobaric interference of ${ }^{176} \mathrm{Lu},{ }^{175} \mathrm{Lu}$ was measured and corrected for mass bias effects, assuming similar behavior to $\mathrm{Yb}(\beta \mathrm{Lu}=\beta \mathrm{Yb})$ and using a ${ }^{176} \mathrm{Lu} /{ }^{175} \mathrm{Lu}$ ratio of 0.02655 (Vervoort et al., 2004). The initial $\varepsilon_{\mathrm{Hf}}$ values were calculated adopting a ${ }^{176} \mathrm{Lu}$ decay constant of $1.865 \times 10^{-11}$ year $^{-1}$ (Scherer et al., 2001), ${ }^{176} \mathrm{Hf} /{ }^{177} \mathrm{Hf}=0.282785$ and ${ }^{176} \mathrm{Lu} /{ }^{177} \mathrm{Hf}=0.0336$ for CHUR (Bouvier et al., 2008). During the sample analysis, ${ }^{176} \mathrm{Hf} /{ }^{177} \mathrm{Hf}$ of $0.282311 \pm 0.0000080(2 \sigma, \mathrm{n}=16)$, and $0.282014 \pm 0.000015(2 \sigma, n=4)$, were measured for standard 91500 and GJ-1 zircons, respectively (Table DR8).

\section{${ }^{40} \mathrm{Ar}{ }^{\beta 9} \mathrm{Ar}$ Geochronology at Oregon State University}

Two basaltic andesite samples from GR were collected for ${ }^{40} \mathrm{Ar} /{ }^{39} \mathrm{Ar}$ dating. Samples were crushed, sieved, washed and dried using standard mineral separation techniques. Once the samples were dried they were sieved to $250-150 \mu \mathrm{m}$. Special care was taken to remove any alteration material by using an intensive acid leaching procedure using a combination of $\mathrm{HCl}$ and $\mathrm{HNO}_{3}$ at different acid strength (Koppers et al., 2000). A final separation of plagioclase was obtained using a binocular microscope. Any visible alteration or adhering crystal phases were carefully removed prior to packaging and irradiation of the sample.

${ }^{40} \mathrm{Ar} /{ }^{39} \mathrm{Ar}$ ages (Table DR9) were obtained by incremental heating methods using the ThermoFisher Scientific ARGUS-VI mass spectrometer and data collection using internal lab software ArArExperiments version 4.4.0. The samples were irradiated for 6 hours (Irradiations 21-OSU-01 in the CLICIT position in the Oregon State University's TRIGA nuclear reactor). Sample were irradiated with the Fish Canyon Tuff sanidine (FCT-2-NM sanidine) with an age of 28.201 $\pm 0.023 \mathrm{Ma}, 1 \sigma$ flux monitor (Kuiper et al. 2008). Individual J-values for each sample were calculated by polynomial extrapolation of the measured flux gradient against irradiation height and typically give $0.06-0.12 \%$ uncertainties $(1 \sigma)$. The ${ }^{40} \mathrm{Ar} /{ }^{39} \mathrm{Ar}$ incremental heating age determinations were performed on a multi-collector ARGUS-VI mass spectrometer at Oregon State University that has 5 Faraday collectors fitted with one (all fitted with two $1012 \mathrm{Ohm}$ resistors: for masses ${ }^{41} \mathrm{Ar}$ and ${ }^{40} \mathrm{Ar}$ and three $1013 \mathrm{Ohm}$ resistors: for argon masses ${ }^{39} \mathrm{Ar},{ }^{38} \mathrm{Ar}$, and ${ }^{37} \mathrm{Ar}$ and 1 ion-counting $\mathrm{CuBe}$ electron multiplier (located in a position next to the lowest mass Faraday collector). This allows us to measure simultaneously all argon isotopes, with mass 36 on the multiplier and masses 37 through 40 on the four adjacent Faradays. This configuration 
provides the advantages of running in a full multi-collector mode while measuring the lowest peak (on mass 36) on the highly sensitive electron multiplier (which has an extremely low dark-noise and a very high peak/noise ratio). Irradiated samples were loaded into $\mathrm{Cu}$-planchettes in an ultra-high vacuum sample chamber and incrementally heated by scanning a Synrad Firestar 20Watt defocused $30 \mathrm{~W} \mathrm{CO}_{2}$ laser beam in pre-set patterns across the sample, in order to release the argon evenly. Each heating step is 62 seconds. After heating, reactive gases were cleaned up using four SAES Zr-Al AP10 getters for 3 minutes; two operated at $450^{\circ} \mathrm{C}$ and two operated at room temperature $\left(21^{\circ} \mathrm{C}\right)$.

Argon isotopic results are corrected for system blanks, radioactive decay, mass discrimination, reactor-induced interference reactions and atmospheric argon contamination after Min et al. (2000). Decay constants reported by Min et al. (2000) are utilized for age calculation. Isotope interference corrections as determined using the ARGUS VI are: $\left({ }^{36} \mathrm{Ar} /{ }^{37} \mathrm{Ar}\right)_{\mathrm{Ca}}=0.0002703 \pm 0.0000005 ;\left({ }^{39} \mathrm{Ar} /{ }^{37} \mathrm{Ar}\right)_{\mathrm{Ca}}=$ $0.0006425 \pm 0.0000059 ;\left({ }^{40} \mathrm{Ar} /{ }^{39} \mathrm{Ar}\right)_{\mathrm{K}}=0.000607 \pm 0.000059 ;\left({ }^{38} \mathrm{Ar} /{ }^{39} \mathrm{Ar}\right)_{\mathrm{K}}=$ $0.012077 \pm 0.000011$. Data reduction and age calculation were processed using Ar-Ar Calc 2.7.0 (Koppers, 2002). Plateau ages are defined as including $>50 \%$ of the total ${ }^{39} \mathrm{Ar}$ released with at least three consecutive steps, where the ${ }^{40} \mathrm{Ar} /{ }^{39} \mathrm{Ar}$ ratio for each step is in agreement with the mean at the $95 \%$ confidence level. In many cases only a mini-plateau age is given, where a mini-plateau $<50 \%$ of the ${ }^{39} \mathrm{Ar}$ released.

\section{Supplementary Figures}




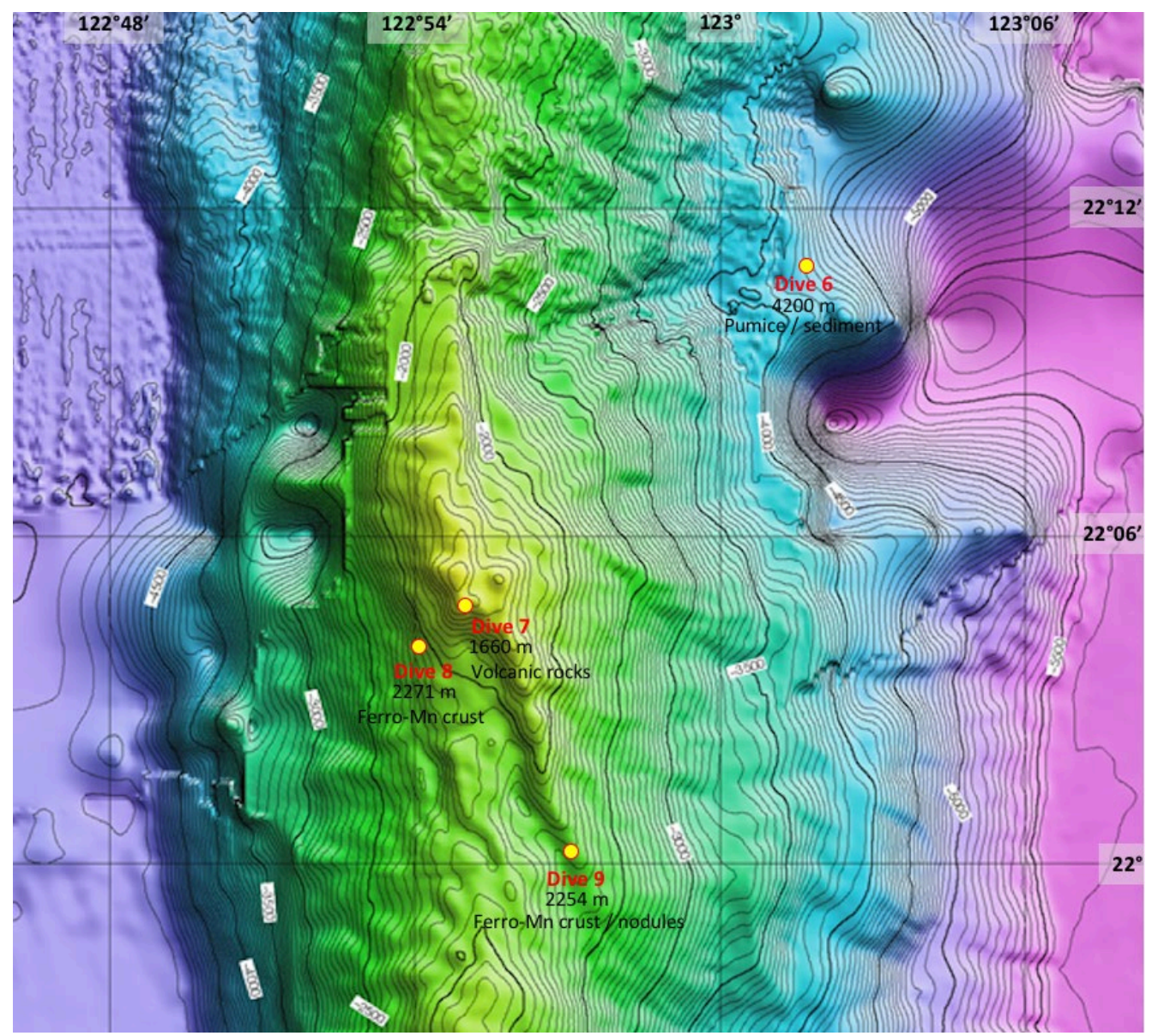

Fig. DR1. Swath bathymetry of the sampling area acquired in 1996 onboard R/V L'Atalante (ACT Cruise, Lallemand et al., 1997). The volcanic rocks discussed in this study were collected at the top of the Gagua Ridge (GR) by ROV during Dive 7. The other area of the Gagua Ridge appears to be covered by sediments and thus the volcanic rocks cannot be sampled by ROV. 

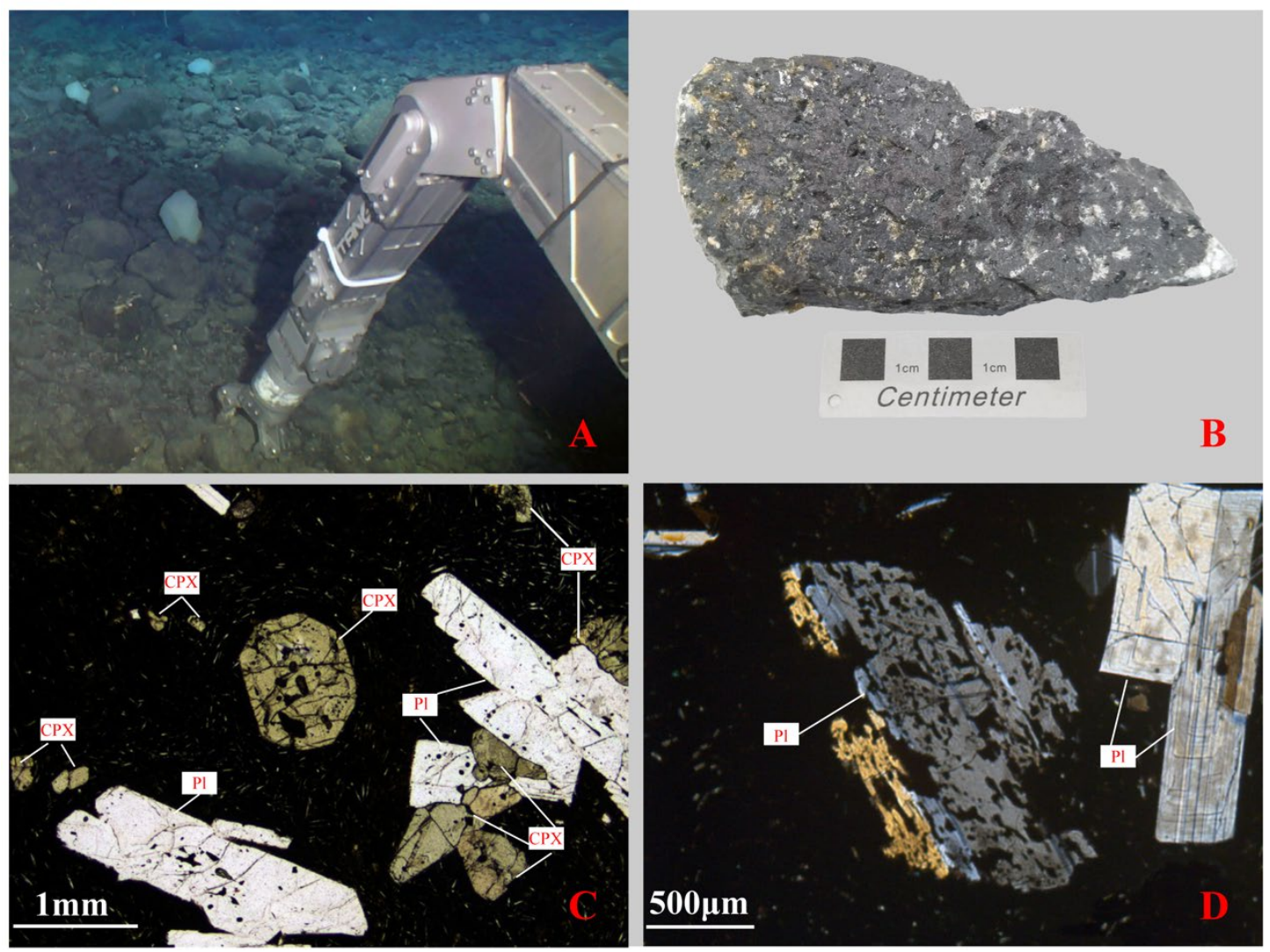

Fig. DR2. Petrographic features of the GR lavas. (A) Rock samples collected by 'PacMan' grab of ROV at $1660 \mathrm{~m}$ below sea level. (B) Photograph of hand specimen of basaltic andesite. (C) Clinopyroxene (Cpx) and Plagioclase (Pl) phenocrysts. (D) Plagioclase phenocryst with resorbed textures. 

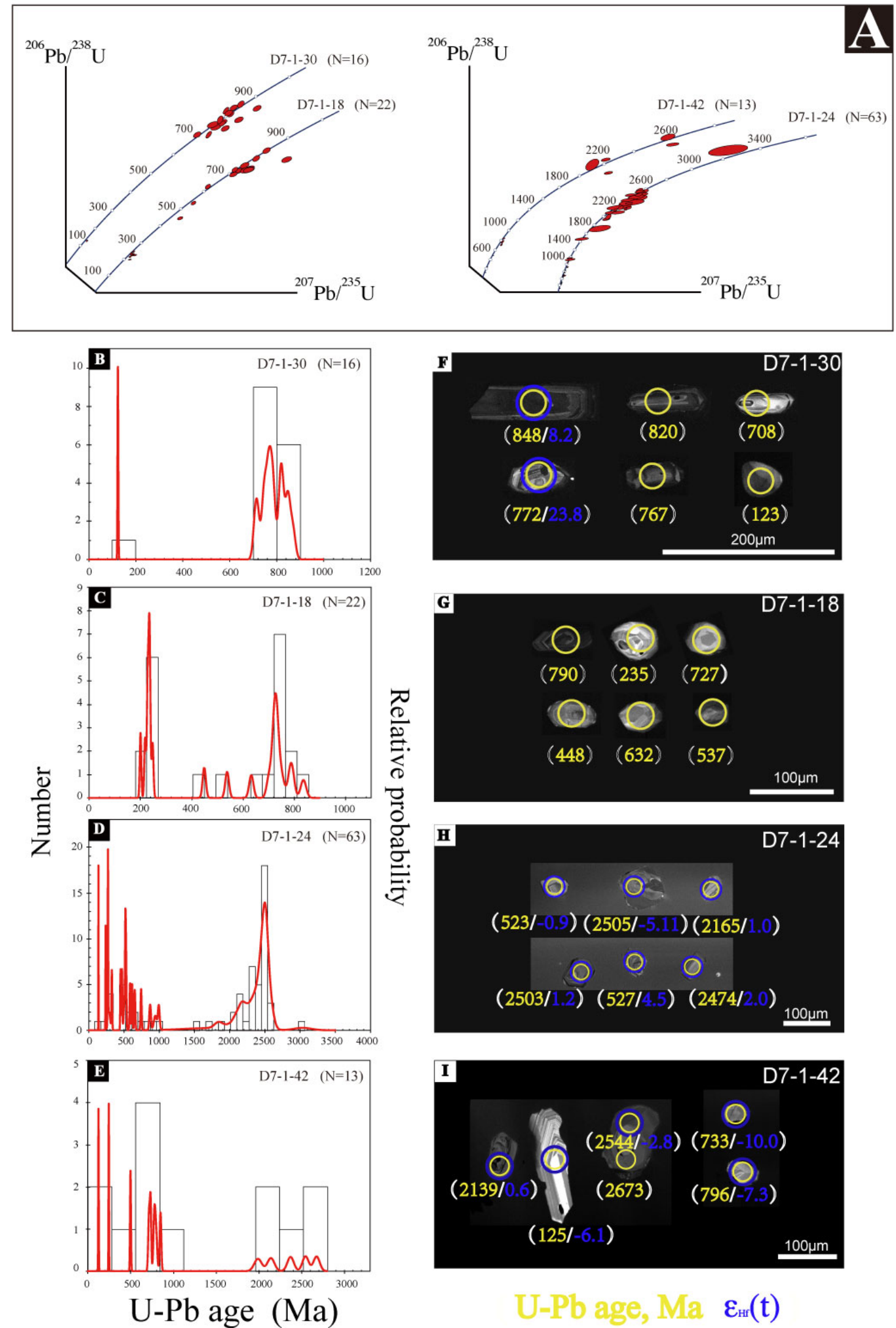

Fig. DR3. Concordia plots and cathodoluminescence (CL)/backscatter electron images of zircons from the GR lavas. Given that $\left({ }^{206} \mathrm{~Pb} /{ }^{238} \mathrm{U}\right)$ age is more precise for young samples, whereas the $\left({ }^{207} \mathrm{~Pb} /{ }^{206} \mathrm{~Pb}\right)$ age is better suited for older samples, 
$\left({ }^{206} \mathrm{~Pb} /{ }^{238} \mathrm{U}\right)$ age are taken for zircons $<1000 \mathrm{Ma}$ and $\left({ }^{207} \mathrm{~Pb} /{ }^{206} \mathrm{~Pb}\right)$ age are used for zircons $>1000 \mathrm{Ma}$ in this study. Zircon crystals vary in morphology and texture from euhedral to subhedral.
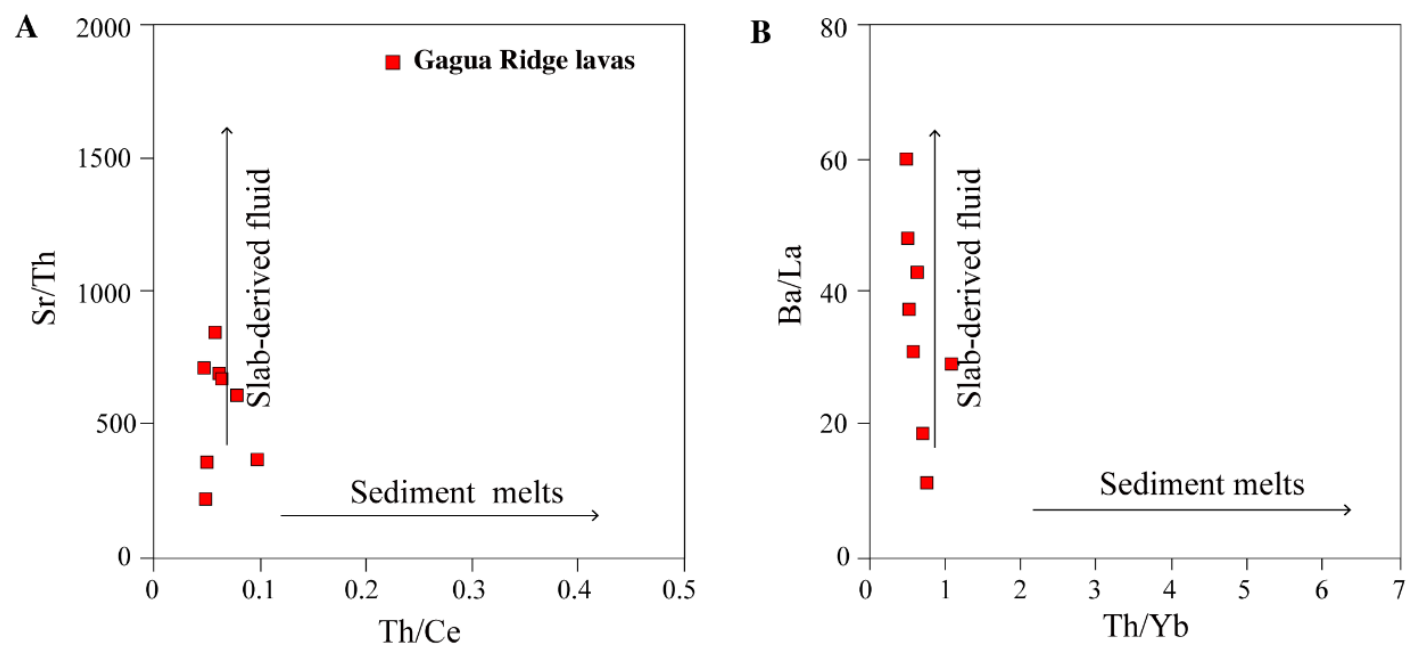

Fig. DR4. $\mathrm{Sr} / \mathrm{Th}$ vs. $\mathrm{Th} / \mathrm{Ce}(\mathrm{A})$, and $\mathrm{Ba} / \mathrm{La}$ vs. $\mathrm{Th} / \mathrm{Yb}(\mathrm{B})$ diagrams for the GR lavas.

\section{Supporting References}

Andersen, T., 2002, Correction of common lead in U-Pb analyses that do not report 204Pb: Chemical Geology, v. 192, no. 1, p. 59-79, doi:https://doi.org/10.1016/S0009-2541(02)00195-X.

Bouvier, A., Vervoort, J. D., and Patchett, P. J., 2008, The Lu-Hf and Sm-Nd isotopic composition of CHUR: Constraints from unequilibrated chondrites and implications for the bulk composition of terrestrial planets: Earth and Planetary Science Letters, v. 273, no. 1, p. 48-57, doi:https://doi.org/10.1016/j.epsl.2008.06.010.

Koppers, A. A. P., 2002, ArArCALC—software for 40Ar/39Ar age calculations: Computers \& Geosciences, v. 28, no. 5, p. 605-619, doi:https://doi.org/10.1016/S0098-3004(01)00095-4.

Koppers, A. A. P., Staudigel, H., and Wijbrans, J. R., 2000, Dating crystalline groundmass separates of altered Cretaceous seamount basalts by the 40Ar/39Ar incremental heating technique: Chemical Geology, v. 166, no. 1, p. 139-158, doi:https://doi.org/10.1016/S0009-2541(99)00188-6.

Kuiper, K. F., Deino, A., Hilgen, F., Krijgsman, W., Renne, P., and Wijbrans, J. R., 2008, Synchronizing Rock Clocks of Earth History: Science, v. 320, p. 500504, doi:10.1126/science.1154339. 
Lallemand S.E., Liu C.-S. and the ACT scientific crew - Swath Bathymetry Reveals Active Arc-Continent Collision Near Taiwan; EOS , Transactions, AGU, 78, 17, 173-175, 1997.

Min, K., Mundil, R., Renne, P. R., and Ludwig, K. R., 2000, A test for systematic errors in 40Ar/39Ar geochronology through comparison with $\mathrm{U} / \mathrm{Pb}$ analysis of a 1.1-Ga rhyolite: Geochimica Et Cosmochimica Acta, v. 64, no. 1, p. 73-98, doi:https://doi.org/10.1016/S0016-7037(99)00204-5.

Scherer, E., Münker, C., and Mezger, K., 2001, Calibration of the Lutetium-Hafnium Clock: Science, v. 293, no. 5530, p. 683-687, doi:10.1126/science.1061372.

Segal, I., Halicz, L., and Platzner, I. T., 2003, Accurate isotope ratio measurements of ytterbium by multiple collection inductively coupled plasma mass spectrometry applying erbium and hafnium in an improved double external normalization procedure: Journal of Analytical Atomic Spectrometry, v. 18, no. 10, p. 1217-1223, doi:10.1039/B307016F.

Vervoort, J. D., Patchett, P. J., Söderlund, U., and Baker, M., 2004, Isotopic composition of $\mathrm{Yb}$ and the determination of $\mathrm{Lu}$ concentrations and $\mathrm{Lu} / \mathrm{Hf}$ ratios by isotope dilution using MC-ICPMS: Geochemistry, Geophysics, Geosystems, v. 5, no. 11, doi:10.1029/2004gc000721.

Zhang, L., Ren, Z.-Y., Xia, X.-P., Yang, Q., Hong, L.-B., and Wu, D., 2019, In situ determination of trace elements in melt inclusions using laser ablation inductively coupled plasma sector field mass spectrometry: Rapid Communications in Mass Spectrometry, v. 33, no. 4, p. 361-370, doi:doi:10.1002/rcm.8359. 